\title{
Futbol Genel Alan Bilgisi Düzeylerinin İncelenmesi: Beden Eğitimi Öğretmenlerinin Değerlendirilmesi
}

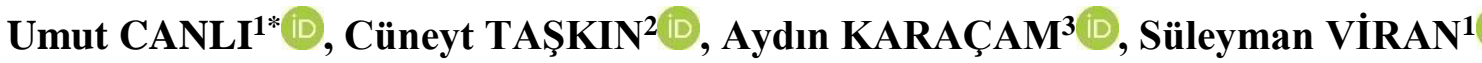 \\ ${ }^{1}$ Tekirdağ Namık Kemal Üniversitesi, Tekirdağ, Türkiye \\ ${ }^{2}$ Trakya Üniversitesi, Edirne, Türkiye \\ ${ }^{3}$ İstanbul Aydın Üniversitesi, İstanbul, Türkiye
}

Orijinal Makale

Gönderi Tarihi: 02.05.2021
Kabul Tarihi: 10.06 .2021
DOI: $10.47778 /$ ejsse. 931434

Online Yayın: 30.06.2021

$\ddot{O} \mathbf{z}$

Araştırmada aktif olarak görev yapan beden eğitimi öğretmenlerinin futbol genel alan bilgisi düzeylerinin farklı değişkenler açısından karşılaştırılması amaçlanmıştır. Veri toplama aracı olarak Beden Eğitimi Öğretmenleri için Futbol Genel Alan Bilgi Testi kullanılmıştır. Araştırmaya 192 beden eğitimi öğretmeni gönüllü olarak katılmıştır. Tüm istatistikler SPSS 18 paket programı kullanılarak yapılmıştır. Katılımcıların özel okulda ve devlet okulunda çalışma durumlarına göre futbol bilgi düzeylerinin karşılaştırılmasında anlamlı bir farklılık tespit edilmemiştir ( $>0.05)$. Katılımcıların yaş aralığ düzeylerine göre futbol bilgi düzeylerinin karşılaştırılmasında anlamlı bir fark tespit edilmiştir $(\mathrm{F}=4.109 ; \mathrm{p}<0.05)$. Bu farkında 22-27 yaş grubundan kaynaklandığ tespit edilmiş $(\mathrm{F}=8.104 ; \mathrm{p}<0.05)$ ve farkın kadrolu grup ile diğer gruplar arasında olduğu tespit edilmiştir. Katılımcıların cinsiyet açısından futbol bilgi düzeylerinin karşılaştırılmasında anlamlı bir farklılık tespit edilmemiştir ( $\mathrm{p}>0.05$ ). Sonuç olarak, katılımcıların özel ya da devlet okullarında çalışıyor olmasının futbol alan bilgisi açısından anlamlı bir fark yaratmadı̆̆ belirlenmiştir. Katılımcıların yaş düzeyi açısından futbol alan bilgisinin karşılaştırılmasında en genç grubun bilgi düzeyinin diğer daha büyük yaş gruplarından az olduğu tespit edilmiştir. Katılımcıların çalışma statüleri açısından yaptığımız değerlendirmede kadrolu grubun futbol alan bilgi düzeyi, ücretli ve sözleşmeli gruptan daha yüksek olarak tespit edilmiştir. Cinsiyet değişkeninin futbol alan bilgisi üzerinde bir etkisi olmadığı belirlenmiştir.

Anahtar kelimeler: Futbol, Beden Eğitimi Öğretmeni, Yeterlik.

\section{Investigation of Football Common Content Knowledge Levels: Assessment of Physical Education Teachers}

\begin{abstract}
The aim of this study is to compare football common content knowledge levels of actively working physical education teachers in terms of different variable. General Football Field Knowledge test was applied on Physical Education Teachers as a data collection tool. 192 physical education teachers voluntarily participated in the study. All statistics were calculated with the SPSS 18 program. No significant difference ( $p>0.05$ ) of football knowledge level was found between participants working in private schools and participants working in public schools. A significant difference was found in the comparison of the football knowledge levels of the participants according to their age range levels $(\mathrm{F}=4.109 ; \mathrm{p}<0.05)$. It was determined that this difference was caused by the 22 27 age group. A significant difference was found in the comparison of the football knowledge levels of the participants according to their working status $(\mathrm{F}=8.104 ; \mathrm{p}<0.05)$. It was determined that this difference is also between the regular group and the other groups. When comparing the football knowledge level of the participants in terms of gender, no significant difference was found ( $>0.05$ ). As a result, it has been determined that whether the participants work in private or public schools does not make a significant difference in terms of football field knowledge. In the comparison of the football field knowledge in terms of age level of the participants, it was found that the knowledge level of the youngest group was lower than the other older age groups. In the evaluation we made in terms of the working status of the participants, the knowledge level of the regular group on football was determined to be higher than the paid and contracted group. It was determined that gender variable has no effect on football field knowledge.
\end{abstract}

Keywords: Football, Physical Education Teacher, Competence.

\footnotetext{
* Sorumlu Yazar: Umut CANLI, E-posta: ucanli@nku.edu.tr
} 


\section{GíRIŞ}

Beden eğitimi derslerinde öğrencilerin isteklerini arttırma ve anlamlı öğrenmeyi destekleme konusunda beden eğitimi öğretmenleri önemli bir role sahiptir (Iserbyt, Ward ve Martens, 2015). Bu rolün ortaya konulmasında en önemli özellik yeterli alan bilgisi düzeyine sahip olmaktır ki bu da öğretilecek konuya hakim olma ve derste etkili öğretim stratejilerini kullanma konularını içine almaktadır. Bu doğrultuda, alan bilgisi kavramı öğretme stratejileri içinde kritik bir öneme sahipken, beceriler ve davranışların öğrenciler tarafından kazanılması gereken özel bilgi olarak tanımlanmaktadır (Shulman, 1987). Beden eğitimi öğretmenlerinin öğretim süreçlerinde yeterli düzeyde alan bilgisine sahip olmaları beklenmektedir. Bu durum, öğrencilerin derslere aktif katılmalarını dolayısıyla dersten öğrencilerin keyif almasına ve istekli olmasına da etki etmektedir. Çünkü, beden eğitimi öğretmenleri yeterli alan bilgisine sahip olmak ile akıc1, eğlenceli ve istenilen kazanımları sağlayacak beceri, bilgi ve yönteme sahip olmaktadır (Graham, 2008). Yapılan bilimsel araştırmalar bu sonuçları destekler niteliktedir. Öğrencilerin öğrenme düzeylerindeki artış ile beden eğitimi öğretmenlerinin alan bilgi düzeyleri arasında anlamlı ilişkilerin olduğu belirtilmektedir (Sinelnikov vd., 2016; Ward vd., 2014), bunun tersi durumun olduğunu gösteren araştırmalar da bulunmaktadır, yani öğretmenlerin yetersiz alan bilgine sahip olması öğrencilerin öğrenme düzeylerini olumsuz bir şekilde etkileyebilmektedir (Stroot ve Ko, 2006). Ülkemizde beden eğitimi öğretmenlerinin alan bilgisi düzeylerini etkileyen unsurlarının neler olduğu konusunda herhangi bir bilgi bulunmamaktadır. Farklı parametrelerin beden eğitimi öğretmenlerinin alan bilgisi düzeyleri üzerinde olumlu ve olumsuz etkiler oluşturabileceği düşünülmektedir.

Alan bilgisi kavramının Ball, Thames ve Phelps (2008) Genel Alan Bilgisi (GAB) ve özelleşmiş alan bilgisi (ÖAB) olarak iki gruba ayrıldığı bilinmektedir. GAB kavramı, bir öğrencinin bir görevi yerine getirmesi için öğretmen tarafindan ihtiyaç duyulan becerileri ve bilgileri kapsamaktadır. ÖAB kavramı ise bir görevi öğretebilmek için sahip olunması gereken bilgi ve becerilerle ilişkilidir. Kavramların anlaşılması için bir örnek ile açıklamak gerekirse; futbolda top sürme tekniğini gösterebilmek için sahip olunması gereken bilgi ve beceri GAB ile ilgilidir, bu tekniğin nasıl öğretileceği konusu ise ÖAB ile ilgili bir konudur.

Beden eğitimi alan bilgisinin dört başlık altında incelendiği görülmektedir. Bunlar sırasıyla, oyun ve görgü kuralları bilgisi, teknik ve taktik bilgisi, öğrenci hataları bilgisi ve öğretim tasarımı ve sunumu bilgisi olacak ayrılmaktadır (Ward, 2009). GAB'ın temel olarak uygulama yoluyla kazanılabileceği yönünde bir görüş bulunmaktadır. GAB kapsamı içerisinde, kural bilgisi, görgü kuralı bilgisi, teknik ve taktik bilgisi gibi konular yer almaktadır. ÖAB ise bir beceriyi öğretmek için gerekli olup öğrenci hataları ve öğretim tasarımı ve sunumu bilgilerine sahip olunmasını gerektirir (Dervent vd., 2018).

Ülkemizde öğretmenlik mesleği genel alan yeterlikleri ve beden eğitimi özel alan yeterlikleri hazırlanan kitaplarda GAB ve ÖAB kavramlarından bahsedilmemiştir (MEB, 2012a; MEB, 2012b). Yurtdışında bulunan önemli eğitim kuruluşları ise GAB ve ÖAB kavramlarına öğretmenliğe yönelik bilgi testlerinde (Educational Testing Service, 2017) ve beden eğitimi 
öğretmenliği standartlarında (SHAPE America, 2017) yer vermişlerdir. Bunun yanında, eğitimin farklı branşlarında öğretmenlerin bilgi düzeyinin belirlenmesi ile ilgili yapılmış çalışmalara rastlamak mümkündür (Hill ve Brodin 2004; Kleickmann vd., 2013). Ancak, alan yazında özellikle ülkemizde beden eğitimi öğretmenlerinin futbol branşı ile ilişkili alan bilgi düzeyinin değerlendirildiği bir çalışmaya rastlanılmamıştır. Dolayısıyla, bu araştırmanın beden eğitimi öğretmenlerinin futbol genel alan bilgisi düzeylerinin belirlendiği ve farklı parametreler üzerinde karşılaştırıldığı ilk araştırma olması, araştırmanın önemini artırmaktadır.

Buradan hareketle, aktif olarak görev yapan beden eğitimi öğretmenlerinin futbol genel alan bilgisi düzeylerinin belirlenerek, genel ve meslek ile ilişkili demografik özellikleri açısından karşılaştırılması araştırmanın amacını oluşturmaktadır.

\section{METOT}

Araştırma modeli: Araştırmada, bir konuya ya da olaya iliş̧in katılımcıların görüşlerinin ya da ilgi, beceri, yetenek ve tutum gibi özelliklerinin belirlendiği tarama yöntemi kullanılmıştır. Araştırma betimsel tarama (survey) modeli kullanılarak gerçekleştirilmiştir. Tarama modeli bir grubun belirli özelliklerini belirlemek için verilerin toplanmasını amaçlayan çalışmalara tarama araştırması denir (Büyüköztürk vd., 2017).

Araştırma grubu: $\mathrm{Bu}$ çalı̧̧mada rastgele seçkisiz örnekleme yöntemi ile Tekirdağ ili ve ilçelerinde görev yapan 192 beden eğitimi öğretmenine ulaşı1mışıtı. Araştırmada kullanılan veri toplama aracı çevrimiçi formlara dönüştürülerek, Tekirdağ ili ve ilçelerindeki tüm beden eğitimi öğretmenlerine mail yolu ile ulaştırılmıştır.

Tablo 1. Katılımcilara ait demografik bilgiler

\begin{tabular}{llc}
\hline Demografik Bilgiler & & $\mathbf{N}$ \\
\hline \multirow{2}{*}{ Cinsiyet } & Erkek & 149 \\
& Kadın & 43 \\
\hline \multirow{3}{*}{ Yaşınız } & $22-27$ & 17 \\
& $28-33$ & 42 \\
& $34-39$ & 58 \\
& $40-45$ & 46 \\
\multirow{2}{*}{ Eğitim Düzeyi } & $46-51$ & 29 \\
\hline \multirow{3}{*}{ Çalışılan Statü } & Lisans & 174 \\
& Lisansüstü & 18 \\
\hline \multirow{2}{*}{ Çalışılan Kurum } & Ücretli & 20 \\
& Sözleşmeli & 29 \\
& Kadrolu & 143 \\
\hline \multirow{3}{*}{ Mesleki Deneyim } & Özel Okul & 26 \\
& Devlet Okulu & 166 \\
\hline & $1-5$ & 41 \\
& $6-10$ & 56 \\
\hline
\end{tabular}


Veri toplama araçları: Katılımcıların genel ve mesleki demografik bilgilerini içeren kişisel bilgi formu veri toplama aracının birinci bölümünde kullanılmıştır. Veri toplama aracının ikinci bölümünde ise Dervent vd., (2018) tarafindan geliştirilmiş olan "Beden Eğitimi Öğretmenleri için Futbol Genel Alan Bilgi Testi” kullanılmıştır. Futbol GAB Testinde her biri 10'ar tane olmak üzere oyun kuralları bilgisi, teknik bilgisi ve taktik bilgisi düzeyini ölçen 24 çoktan seçmeli soru bulunmaktadır. Rasch modeli kullanılarak yapılan güvenirlik ve geçerlik değerlendirmesi 24 sorunun uyum indekslerinin kabul edilen düzeyin üzerinde olduğunu ortaya koymuştur. Test sorularına verilen her doğru cevap 1 puan olarak hesaplanmış ve testin sonunda elde edilen toplam puan hesaplanarak kaydedilmiştir. Test sorularına verilen yanlış cevaplar doğru cevapları etkilemeyerek, toplam doğru cevap sayısı üzerinden değerlendirmeler yapılmıştır.

Verilerin analizi: Araştırmanın verilerin normal dağılıp dağılmadığını tespit edebilmek için basıklık (kurtosis), çarpıklık (skewness) değerlerine bakılarak kontrol edilmiştir. Basıklık ve çarpıklık sonuçlarına göre elde edilen değerlerin $\pm 1,5$ arasında olması verilerin normal dağılım gösterdiğini, bu ölçüler dışındaki değerlerin normal dağılım göstermediğini yapılan çalışmalar göstermiştir (Tabachnick ve Fidell, 2013). Araştırma verilerinin normallik dağılımlarına bakıldığında, verilerin normal dağılım sergilediği tespit edilmiştir (Tablo 2).

Tablo 2. Verilere ait normallik testi sonuçları

\begin{tabular}{cccccc}
\hline Ortalama & $\begin{array}{c}\text { Standart } \\
\text { Sapma }\end{array}$ & Minimum & Maksimum & Basıklık Değeri & Çarpıklık Değeri \\
\hline 15.0625 & 3.4559 & 3 & 24 & $-0,471(0,175)$ & $0,175(0,349)$ \\
\hline
\end{tabular}

Araştırmanın bağımsız değişkenlerinden "cinsiyet", "çalışılan kurum" ve "eğitim düzeyi" değişkenlerinin karşılaştırılmasında bağımsız örneklemler T-Testi, diğer değişkenler olan "yaş aralığı", "çalışma statüsü" ve "mesleki deneyim" değişkenlerini karşılaştırmak için ise tek yönlü varyans analizi kullanılmıştır. Analizler sonucunda istatistiksel olarak anlamlı farklılık çıkan testlerde farklılaşmanın kaynağını tespit edebilmek için post-hoc testlerinden LSD ve Tamnhane's T2 yapılmıştır. Son olarak anlamlı farklılık tespit edilen tek yönlü varyans analizi deseninde değişkenler arasındaki ilişkinin gücünü hesaplamak için eta-kare (etki büyüklüğü) $\left(\eta^{2}\right)$ katsayısından faydalanılmıştır (Büyüköztürk vd., 2017). Eta-kare değeri; “ $\eta^{2}=$ Gruplar arası kareler toplamı $\div$ Kareler toplamı” formülü ile hesaplanmıştır. 


\section{BULGULAR}

Tablo 3. Katılımcıların futbol bilgi düzeylerinin cinsiyet, çalışılan kurum ve eğitim düzeyi değişkenlerine göre karşılaştırma sonuçları

\begin{tabular}{|c|c|c|c|c|c|c|c|}
\hline \multicolumn{2}{|c|}{ Değişkenler } & $\mathbf{N}$ & $\overline{\mathbf{x}}$ & Ss & Sd. & $\mathbf{t}$ & $\mathbf{p}$ \\
\hline \multirow{2}{*}{ Cinsiyet } & Erkek & 149 & 15.20 & 3.24 & \multirow{2}{*}{190} & \multirow{2}{*}{1.441} & \multirow{2}{*}{0.151} \\
\hline & Kadın & 43 & 14.39 & 4.06 & & & \\
\hline \multirow{2}{*}{$\begin{array}{l}\text { Çalışılan } \\
\text { Kurum }\end{array}$} & Özel Okul & 26 & 14.23 & 3.47 & \multirow{2}{*}{190} & \multirow{2}{*}{1.322} & \multirow{2}{*}{0.188} \\
\hline & Devlet Okulu & 166 & 15.19 & 3.44 & & & \\
\hline \multirow{2}{*}{$\begin{array}{l}\text { Eŭitim } \\
\text { Düzeyi }\end{array}$} & Lisans & 174 & 15.07 & 3.52 & \multirow{2}{*}{190} & \multirow{2}{*}{0.152} & \multirow{2}{*}{0.879} \\
\hline & Lisansüstü & 18 & 14.94 & 2.75 & & & \\
\hline
\end{tabular}

Katılımcıların futbol bilgi düzeylerinin; cinsiyet, çalışılan kurum ve eğitim düzeyi değişkenlerine göre karşılaştırılmasında her üç değişken içinde istatistiksel olarak anlamlı fark tespit edilmemiştir ( $>0.05$ ). Bağımsız demografik değişkenlerin futbol bilgi düzeyleri üzerinde etkin bir farklılığa yol açmadığı görülerek, tüm test sonuçlarına ait ortalamaların birbirine yakın olduğu belirlenmiştir.

Tablo 4. Katılımcıların futbol bilgi düzeylerinin yaş aralığı, çalışılan statü ve mesleki deneyim değişkenlerine göre karşılaştırma sonuçları

\begin{tabular}{|c|c|c|c|c|c|c|c|c|c|c|c|}
\hline & Değişkenler & $\mathbf{N}$ & $\overline{\mathbf{x}}$ & S. & $\begin{array}{l}\text { Kareler } \\
\text { Toplamı }\end{array}$ & Sd. & $\begin{array}{c}\text { Kareler } \\
\text { Ortalaması }\end{array}$ & $\mathbf{F}$ & $\mathbf{p}$ & $\begin{array}{l}\text { Farkın } \\
\text { Kaynağı }\end{array}$ & $\begin{array}{c}\text { Etki } \\
\text { Değeri }\end{array}$ \\
\hline \multirow{5}{*}{ 离 } & 22-27 yaş & 17 & 12.29 & 4.41 & & & \multirow{5}{*}{$\begin{array}{l}46.080 \\
11.214\end{array}$} & \multirow{5}{*}{4.109} & \multirow{5}{*}{$0.003 *$} & $22-27$ yaş & \multirow{5}{*}{0.284} \\
\hline & 28-33 yaş & 42 & 14.64 & 3.88 & 184.321 & 4 & & & & 1 & \\
\hline & 34-39 yaş & 58 & 15.93 & 3.04 & 2096.929 & 187 & & & & $34-39$ yaş (3.63) & \\
\hline & 40-45 yaş & 46 & 15.21 & 2.57 & 2281.250 & 191 & & & & 40-45 yaş (2.92) & \\
\hline & 46-51 yaş & 29 & 15.31 & 3.47 & & & & & & $46-51$ yaş (3.01) & \\
\hline \multirow{3}{*}{ 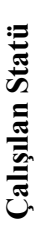 } & Ücretli & 20 & 13.35 & 3.03 & & & \multirow{3}{*}{$\begin{array}{l}90.085 \\
11.117\end{array}$} & \multirow{3}{*}{8.104} & \multirow{3}{*}{$0.000^{*}$} & Kadrolu & \multirow{3}{*}{0.281} \\
\hline & Sözleşmeli & 29 & 13.44 & 4.44 & 2101.079 & 189 & & & & l & \\
\hline & Kadrolu & 143 & 15.62 & 3.10 & 2281.250 & 191 & & & & $\begin{array}{c}\text { Ücretli (2.27) } \\
\text { Sözleşmeli (2.18) }\end{array}$ & \\
\hline \multirow{5}{*}{ 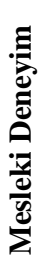 } & $1-5$ yıl & 41 & 13.60 & 3.84 & \multirow{5}{*}{$\begin{array}{c}140.298 \\
2140.952 \\
2281.250\end{array}$} & \multirow{5}{*}{$\begin{array}{c}4 \\
187 \\
191\end{array}$} & \multirow{5}{*}{$\begin{array}{l}35.074 \\
11.449\end{array}$} & \multirow{5}{*}{3.064} & \multirow{5}{*}{$0.018 *$} & \multirow{3}{*}{$11-15$ y1l (2.23) } & \multirow{5}{*}{0.247} \\
\hline & 6-10 yil & 56 & 15.17 & 3.11 & & & & & & & \\
\hline & 11-15 yıl & 39 & 15.84 & 3.58 & & & & & & & \\
\hline & $16-20$ yıl & 14 & 16.50 & 3.22 & & & & & & $16-20$ y1l (2.89) & \\
\hline & 21 ve üzeri & 42 & 15.11 & 3.10 & & & & & & & \\
\hline
\end{tabular}

$* \mathbf{p}<0.05$

Araştırma grubunun futbol genel alan bilgi düzeyi ile yaş aralıkları, çalışma statüleri ve mesleki deneyim yılları bakımından istatistiksel olarak anlamlı farklılık tespit edilmiştir $(p<0.05)$. 
Katılımcıların yaşları ile futbol genel alan bilgi düzeyleri arasındaki anlamlı farklılığın $\left[\mathrm{F}_{(4-187)}=\right.$ 4.109, $\mathrm{p}<0.05$ ] hangi değişkenlerden kaynaklandığını bulabilmek için post-hoc testleri kullanılmıştır. Bu test sonuçlarına göre; 22-27 yaş ile 34-39 yaş, 40-45 yaş ve 46-51 yaş değişkenleri arasında farklılık tespit edilmiştir. Bu farklılığın kaynağı olan, istatistiksel ilişkinin gücünü hesaplamak için eta-kare (etki büyüklüğ̈̈) $\left(\eta^{2}\right)$ katsayısı kullanılmıştır (Büyüköztürk, Çokluk, Köklü, 2019). Hesaplamalar sonucu etki büyüklügü; eta-kare $\left(\eta^{2}\right)=0.284$ olarak hesaplanmıştır. Buna göre, katılımcıların futbol genel alan bilgi düzeyine ait toplam varyansın \%28'i katılımcıların yaş aralığı değişkeni ile açıklandığı söylenebilir. Etki büyüklüğü değeri (0.284); katılımcıların yaş düzeylerinin futbol bilgi seviyeleri üzerinde, yüksek düzey etkiye sahip olduğunu göstermektedir (Cohen, 1988).

Katılımcıların çalışma statüleri açısından futbol genel alan bilgi düzeylerinin karşılaştırması sonucunda; katılımcıların çalışma statüleri arasında futbol genel alan bilgi düzeyleri açısından istatistiksel olarak anlamlı farklılık tespit edilmiştir $\left[\mathrm{F}_{(2-189)}=8.104, \mathrm{p}<0.05\right] . \mathrm{Bu}$ farklılığın tespiti için yapılan post-hoc testlerine göre farkl1lık; kadrolu çalışanlar ile ücretli ve sözleşmeli çalışanlar arasında olduğu belirlenmiştir. Etki büyüklüğü $\left(\eta^{2}=0.281\right)$ katılımcıların çalışma statülerinin futbol genel alan bilgi düzeyleri üzerinde, yüksek düzey etkiye sahip olduğunu göstermektedir (Cohen, 1988). Buna göre, katılımcıların futbol genel alan bilgi düzeyine ait toplam varyansın \%28'i katılımcıların çalışma statüleri ile açıklandığı söylenebilir.

Katılımcıların futbol genel alan bilgi düzeylerinin mesleki deneyim açısından karşılaştırmasında gruplar arasında anlamlı farklılıklar tespit edilmiştir $\left[\mathrm{F}_{(4-187)}=3.064, \mathrm{p}<0.05\right] . \mathrm{Bu}$ farklılığın; 1-5 yıl ile 11-15 yıl ve 16-20 yıl çalışanlar arasında olduğu post-hoc testleri ile belirlenmiştir. Etki büyüklüğüne $\left(\eta^{2}=0.247\right)$ göre, katılımcıların mesleki deneyim olarak çalışma yıllarının futbol genel alan bilgi düzeyleri üzerinde yüksek düzey etkiye sahip olduğunu görülmektedir (Cohen, 1988). Bu bağlamda katılımcıların futbol genel alan bilgi düzeyine ait toplam varyansın \%24'ü katılımcıların çalışma statüleri ile açıklandığı söylenebilir.

\section{TARTIŞMA VE SONUÇ}

$\mathrm{Bu}$ araştırma aktif olarak görev yapan beden eğitimi öğretmenlerinin futbol genel alan bilgi düzeylerinin genel ve mesleki demografik özellikleri açısından karşılaştıılması amacıyla yapılmıştır.

Futbol GAB düzeylerinin cinsiyet değişkeni açısından değerlendirmesinde erkek öğretmenlerin ve kadın öğretmenlerin ortalama puanlarının birbirlerine oldukça yakın oldukları belirlenmiş ve istatistiksel olarak bu iki grup arasında anlamlı bir fark tespit edilmemiştir. Ülkemizde ve dünyada futbolun daha çok erkekler tarafindan takip edildiği bilinmekle birlikte küçük yaşlardan itibaren futbol oynayan erkeklerin kadınlardan daha fazla bilgiye sahip olmaları beklenen bir durum olarak düşünülmektedir. Alan yazında beden eğitimi öğretmenlerinin futbol genel alan bilgi düzeyini cinsiyet değişkeni açısından inceleyen bir araştırmaya rastlanılmamıştır. Ancak, beden eğitimi alan bilgisi derslerinde kız öğrencilerin erkek öğrencilere göre daha başarılı oldukları ve alan bilgisi 
derslerinde akademik başarının kız öğrenciler lehine anlamlı çıktığı, kız öğrencilerin daha yüksek akademik motivasyona sahip olmalarının ve öğrenme stratejilerini daha iyi kullanmaları ile ilişkilendirilebileceği şeklinde bir yorum yapılabilir (Işıkgöz, Dinçer ve Kıılıç, 2016).

Araştırmada diğer bir değişken olan "çalışılan kurum" başlı̆̆ altındaki durum analiz edildiğinde; devlet okullarında görev yapan beden eğitimi öğretmenlerinin özel okullarda görev yapan beden eğitimi öğretmenlerinin futbol genel alan bilgi düzeyi puanlarından daha yüksek olduğu belirlenmiştir. Ancak, bu iki grup arasında puan düzeyi açısından istatistiksel olarak anlamlı bir fark bulunmamaktadır. Alan yazında bu bulgular ile ilişkili bir çalışmaya rastlanılmamıştır. Ancak bu bulgu; özel okullarda saha ve malzeme imkanlarının daha fazla olması, dolayısıyla futbol branşı dışında farklı pek çok spor dalı öğretimine odaklanılması özel okullarda görev yapan öğretmenlerin futbol genel alan bilgilerini derinlemesine incelemelerini ve öğrenmelerini etkilemiş olabilir. Yine bir başka araştırma değişkeni olan eğitim düzeyi açısından yapılan değerlendirmede beklenenin dişında bir sonuç ile karşılaşılmıştır. Lisans mezunu beden eğitimi öğretmenlerinin lisansüstü mezunlarına göre daha yüksek bilgi düzeyi puanlarına sahip olduğu belirlenmiştir. Ancak, bu iki grup arasında bilgi düzeyi puanları açısından istatistiksel olarak anlamlı farklılık tespit edilmemiştir. Bu sonucun ortaya çıkmasında birçok faktörün etkili olabileceği düşünülmektedir. Bunlardan biri, lisansüstü mezunu öğretmenlerin futbol branş1 dışında bir uzmanlık alanıyla ilgili olmalarının futbol bilgilerini olumsuz yönde etkileyebileceği varsayımı ile açıklanabilir.

Öğretmenlerin yaşları ile aldıkları puanlar arasında anlamlı farklılık tespit edilmiştir. Bu farklılığın mesleğe yeni başlayan (22-27 yaş) öğretmenler ile yaşı ilerlemiş (34-51 yaş aralığı) öğretmenler arasında olduğu görülmektedir. Buradan hareketle, mesleki tecrübe, okul içi ve okul dış1 eğitimlerde futbol branşına ağırlık verilmesi ve bunlarla ilişkili olarak futbol branşı ile geçilen zamanın daha fazla olması ortaya konan bu sonuç ile açıklanabilir. Çalışma statüsü açısından yapılan analiz sonuçlarına göre; kadrolu statüde görev yapan öğretmenler ile ücretli ve sözleşmeli statüde görev yapan öğretmenlerin futbol GAB puan ortalamaları arasında istatistiksel olarak anlamlı farklılıklar belirlenmiştir. Bu farklılığın nedeninin, kadrolu çalışanların iş kaybı korkusu olmadan çalışmalarından kaynaklanabileceği düşünülmektedir. Araştırmanın bu sonucu ile ilgili alan yazında herhangi bir araştırmaya rastlanılmamıştır. Öğretmenlerin yaş değişkenine benzer bir diğer sonuç mesleki deneyim değişkeninde de belirlenmiş̧ir. Öğretmenlerin mesleki deneyim yılları ile futbol GAB testinden aldıkları puan ortalamaları arasında istatistiksel olarak anlamlı farklılık belirlenmiştir. Farklılı̆̆ın kaynağı olarak 1-5 yıl arası deneyim ile 11 ve üzeri yıl arası deneyim sahibi grupların arasında olduğu tespit edilmiştir. Mesleki deneyim arttıkça futbol GAB düzeyinin de arttığı ortaya konulmuştur.

Sonuç olarak; araştırma grubumuzda yer alan beden eğitimi öğretmenlerinin futbol genel alan bilgisi düzeyleri üzerinde cinsiyet faktörünün bir etkisi olmadığı belirlenmiştir. Bununla beraber beden eğitimi öğretmenlerinin devlet ya da özel okulda çalışması ve lisans ya da lisansüstü eğitim düzeyine sahip olması futbol genel alan bilgi düzeyini etkilememektedir. Kadrolu statüde görev yapmak, yaş düzeyi ve mesleki tecrübenin yüksek olması futbol genel alan bilgi düzeyinin yüksek 
olmasına etki eden parametreler olarak belirlenmiştir. Bu sonuçlar ile ilişkili olarak bazı önerilerde bulunulabilir. Özellikle, mesleki deneyim yılı fazla olan öğretmenlerin mesleğe yeni başlayan öğretmenler ile bir araya getirilerek bilgi ve tecrübe paylaşımı yapmaları sağlanabilir. Belirli zaman dilimleri içerisinde beden eğitimi öğretmenlerine alan ile ilgili güncel bilgilerin aktarıldığ 1 çeşitli eğitsel faaliyetler düzenlenerek, mesleki gelişim süreçlerine katkı sağlayabilir. Çalışma Tekirdağ İli ile sınırlandırılmış olup benzer çalışmalar farklı şehirlerde ya da bölgelerde yapılabilir ve bu çalışma da akademisyenlere referans olarak katkı sağlayabilir.

Çıkar Çatışması: Yazarlar arasında çıkar çatışması olmadığını beyan ederiz.

Yayın Etiği: Mevcut çalışmanın yazım sürecinde "Yükseköğretim Kurumları Bilimsel Araştırma ve Yayın Etiği Yönergesi” kapsamında bilimsel, etik ve alıntı kurallarına uyulmuş olup; toplanan veriler üzerinde herhangi bir tahrifat yapılmamış ve bu çalışma herhangi başka bir akademik yayın ortamına değerlendirme için gönderilmemiştir.

\section{KAYNAKÇALAR}

Ball, D.L., Thames, M.H. \& Phelps, G. (2008). Content knowledge for teaching: What makes it special? Journal of Teacher Education, 59, 389-407.

Büyüköztürk, Ş., Çokluk, Ö. ve Köklü, N. (2019). Sosyal bilimler için istatistik. İstanbul: Pegem Akademi.

Büyüköztürk, Ş., Çakmak, E. K. Akgün, Ö. E., Karadeniz, Ş. ve Demirel, F. (2017). Bilimsel araştırma yöntemleri. İstanbul: Pegem Akademi.

Cohen, J. (1988). Statistical power analysis for the behavioral sciences, 2nd ed. Hillsdale, New Jersey: Erlbaum

Dervent, F., Devrilmez, E., İnce, M. L. ve Phillip, W. (2018). Beden eğitimi öğretmenleri için futbol genel alan bilgisi bilgi testinin güvenirlik ve geçerliği. Spor Bilimleri Dergisi, 29(1), 39-52.

Educational Testing Service. (2017). Gain a deeper understanding of specialized content knowledge your teachers need to succeed. Mayis 12, 2020, https://www. ets.org/s/praxis/pdf/praxis_ckt.pdf

Graham, S. (2008). Effective writing instruction for all students. Renaissance learning. https://doc.renlearn.com/KMNet/R004250923GJCF33.pdf [Erişim tarihi: 04.03.2021].

Hill, G. \& Brodin, K.L. (2004). Physical education teachers' perceptions of the adequacy of university coursework in preparation for teaching. Physical Educator, 61(2), 75-87.

Iserbyt, P., Ward, P. \& Martens, J. (2016). The influence of content knowledge on teaching and learning in traditional and sport education contexts: An exploratory study. Physical Education and Sport Pedagogy, 21(5), 539556.

Işıkgöz, E., Dinçer, N. ve Kılınç, Z. (2016). Beden eğitimi öğretmen adaylarının öğretmenlik meslek bilgisi dersleri ile alan bilgisi ders başarıları arasındaki ilişkinin incelenmesi (Batman Üniversitesi örneği). Batman Üniversitesi Yaşam Bilimleri Dergisi, 6(2/1), 338-346. 
Canlı, U., Taşkın, C., Karaçam, A. ve Viran, S. (2021). Futbol genel alan bilgisi düzeylerinin incelenmesi: Beden eğitimi öğretmenlerinin değerlendirilmesi. Avrasya Spor Bilimleri ve Eğitim Dergisi, 3(1), 40-50.

Kleickmann, T., Richter, D., Kunter, M., Elsner, J., Besser, M., Krauss, S. \& Baumert, J. (2013). Teachers' content knowledge and pedagogical content knowledge: The role of structural differences in teacher education. Journal of teacher education, 64(1), 90-106.

Milli Eğitim Bakanlığı. (2012a). Beden eğitimi öğretmeni özel alan yeterlikleri. Ocak 12, 2017, http:// otmg.meb.gov.tr/belgeler/ogretmen_yeterlikleri_ kitabi/Öğretmen_Yeterlikleri_ Kitab1_beden_eğitimi_ öğretmeni_özel_alan_yeterlikleri_ilköğretim_parç̧a_14.pdf 27.

Milli Eğitim Bakanlığı. (2012b). Öğretmenlik mesleği genel yeterlikleri. Ocak 12, 2017, http://otmg.meb.gov.tr/belgeler/ogretmen_yeterlikleri_kitabi/Öğretmen_Yeterlikleri_Kitab1_genel_yeterlikl er_parça_2.pdf

Shulman, L.S. (1987). Knowledge and teaching: Foundations of the new reform. Harvard Educational Review, 57, 122.

Sinelnikov, O.A. Kim, I., Ward, P., Curtner-Smith, M. \& Li, W. (2016). Changing beginning teachers' content knowledge and its effects on student learning. Physical Education and Sport Pedagogy, 21(4), 425-440.

Stroot, S.A. \& Ko, B. (2006). Induction of beginning physical educators into the school setting In D. Kirk, D. Macdonald, and M. O'Sullivan (Eds.), The Handbook of Physical Education. s. 425-448. Berkeley: Sage.

Tabachnick, B.G. \& Fidell, L.S. (2013). Using multivariate statistics. 6th ed. Boston: Allyn and Bacon.

Ward, P., Kim, I., Ko, B. \& Li, W. (2014). Effects of improving teachers' content knowledge on teaching and student learning in physical education. Research Quarterly for Exercise and Sport, 86, 130-139. doi:10.1080/02701367 .2014.987908

Ward, P. (2009) Content matters: Knowledge that alters teaching. In L. Housner, M. Metzler, P. Schempp and T. Templin (edt.), Historic traditions and future directions of research on teaching and teacher education in physical education (pp. 345-356) Morgantown WV: Fitness Information Technology. 


\section{EXTENDED ABSTRACT}

\section{Investigation of Football Common Content Knowledge Levels: Assessment of Physical Education Teachers}

\section{Introduction}

Physical education teachers have an important role in increasing students' desire in physical education classes and supporting meaningful learning (Iserbyt, Ward, \& Martens, 2015). The most important feature in revealing this role is to have sufficient level of field knowledge, which includes the subjects of mastering the subject to be taught and using effective teaching strategies in the lesson. While the concept of field knowledge has a critical importance in teaching strategies, it is defined as special knowledge that skills and behaviors must be acquired by students (Shulman, 1987). Physical education teachers are expected to have sufficient field knowledge in their teaching processes. This situation also affects the active participation of the students in the lessons, thus the students' pleasure and willingness. In our country, there is no study that evaluates the level of knowledge of physical education teachers related to any sport branch. Therefore, the fact that this study is the first to determine the general field knowledge of physical education teachers and compare them on different parameters increases the importance of the study.

\section{Method}

General Football Field Knowledge test was applied on Physical Education Teachers as a data collection tool. 192 physical education teachers voluntarily participated in the study. Kurtosis and skewness values were used for normality tests. It was found that the data was normally distributed. Independent sample $\mathrm{T}$ test was used for the comparison of two variables. One-way analysis of variance (ANOVA) was used for the comparison of more than two variables. Taking into account the equality of the homogeneity of the variances, post hoc analyses were executed with LSD and Tamhane's T2 test. All statistics were calculated with the SPSS 18 program.

\section{Findings}

No significant difference ( $\mathrm{p}>0.05$ ) of football knowledge level was found between participants working in private schools and participants working in public schools. A significant difference was found in the comparison of the football knowledge levels of the participants according to their age range levels $(\mathrm{F}=4.109 ; \mathrm{p}<0.05)$. LSD post hoc analysis was conducted to determine from which group this difference originated. As a result of the results obtained from this test, a significant difference was found between the 22-27 age group and all other groups. A significant difference was found in the comparison of the football knowledge levels of the participants according to their working status $(\mathrm{F}=8.104$; $\mathrm{p}<0.05)$. Tamhane's $\mathrm{T} 2$ post hoc analysis was conducted to determine from which group this difference arises. As a result of the results obtained from this test, a significant difference was found between the regular group and the other groups. 
Canlı, U., Taşkın, C., Karaçam, A. ve Viran, S. (2021). Futbol genel alan bilgisi düzeylerinin incelenmesi: Beden eğitimi öğretmenlerinin değerlendirilmesi. Avrasya Spor Bilimleri ve Ĕgitim Dergisi, 3(1), 40-50.

When comparing the football knowledge level of the participants in terms of gender, no significant difference was found $(\mathrm{p}>0.05)$.

\section{Discussion and Conclusion}

It was determined that the gender factor did not have an effect on the football general field knowledge of the physical education teachers in our research group. However, the fact that physical education teachers work in public or private schools and have undergraduate or postgraduate education level does not affect the general field knowledge level of football. Working in permanent status, age level and high professional experience are determined as parameters that affect the high level of general knowledge of football. Some suggestions can be made in relation to these results. In particular, teachers with more years of professional experience can be brought together with new teachers to share knowledge and experience. Contribution can be made to professional development processes by organizing various educational activities in which up-todate information about the field is conveyed to physical education teachers within certain time periods.

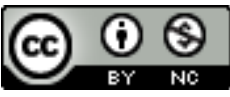

Bu eser Creative Commons Atıf-Gayri Ticari 4.0 Uluslararası Lisansı ile lisanslanmıştır. 